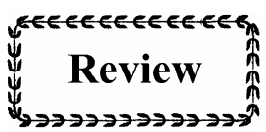

\title{
Progress in studies on the structure and physical properties of the mantle in China *
}

\author{
ZANG Shao-xian ${ }^{1), *}$ (藏绍先) ZHOU Hui-lan ${ }^{2)}$ (周德兰) WEI Rong-qiang ${ }^{1,2)}$ (魏荣强)
}

1) Department of Geophysics, Peking University, Beijing 100871, China

2) Graduate University, Chinese Academy of Sciences, Beijing 100049, China

\begin{abstract}
The studies on the structure and physical properties of the mantle by Chinese geophysicists from 2003 to 2007 are reviewed in this report. It mainly contains studies on the seismic velocity structure of the mantle, anisotropy of the mantle, mantle discontinuities, mantle convection and the physical properties of mantle. The review concerns mainly the contents, the methods used and the results of the studies. It can be found that new progress in the study on the structure and physical properties of mantle has been made in the last four years in China. In some preexistent areas much progress has been made, advanced methods have been adopted, extensive international co-operation has been conducted in many ways, and the scope of the co-operation has gradually expanded. Moreover, some new fields appear as well.
\end{abstract}

Key words: mantle structure; physical property of the mantle; mantle discontinuity; mantle convection; seismic velocity anisotropy

CLC number: P315.2 Document code: A

\section{Introduction}

Progress in the study on the structure and physical properties of the mantle has been made in the past four years. ZANG et al (2003) has reviewed the studies on the structure and the physical properties of the Earth's interior in China during 1999 2003. Following such work this review summarizes the work done by Chinese geophysicists on the structure and physical properties of the mantle from 2004 to 2007. The contents are mainly on the structure and physics of the mantle beneath the lithosphere and therefore may be limited. Related results can be found in other reviews.

\section{Seismic velocity structure of the mantle}

In the past four years, the seismic velocity structure of the mantle is still an important research field in China. The areas of study are mainly Chinese mainland and its adjacent region. The main methods are seismic tomography and receiver functions.

\subsection{Seismic tomography of the mantle structure}

Huang and Zhao (2006) determined a high-resolution P wave tomographic model of the crust

\footnotetext{
* Received 2008-02-02; accepted in revised form 2008-07-21.

Foundation item: National Natural Science Foundation of China (40604006).

* Author for correspondence: sxzang@pku.edu.cn
} 
and mantle down to $1100 \mathrm{~km}$ depth under China and surrounding regions using about one million arrival times of P, pP, PP, and PcP waves. Their model shows the subduction state of the Pacific, Mariana, Indian and Philippine Sea subduction zones, and the relationship between the volcanoes and subduction zones. Moreover, it can be seen from their model that high-velocity anomalies are revealed in the upper mantle under the Tarim basin, Ordos, and Sichuan basin. HE et al (2006) studied the seismic velocity structure of the lithospheric mantle beneath the western Kunlun orogenic belt (WKOB) and its foreland by a tomographic method using $\mathrm{P}$ wave arrival times recorded by 14 broadband stations. Their results show that the lithospheric mantle beneath WKOB is perhaps the frontier of the subducted lithospheric mantle of the Indian Plate; the lithospheric mantle beneath WKOB with high-velocity anomalies collided with that of the Tarim blocks with low velocity anomalies at the depths from $150 \mathrm{~km}$ to $300 \mathrm{~km}$. By using four seismic tomographic profiles of nearly $8000 \mathrm{~km}$ long across the Tibetan Plateau, XU et al (2004) obtained crustal and mantle velocity images and seismic wave anisotropy over the depth down to $400 \mathrm{~km}$, which revealed significant characteristics of the crust and mantle structure in the studied region. The depth extending downward of the strike-slip faults and the subduction northward of the Indian plate are discussed in their paper. Based on the new tomographic data a new collisional model for the uplift of the Tibetan Plateau is presented. ZHAO et al (2004a) used 24241 rays from 926 distant events recorded at 164 portable stations along the cross section of Yadong-Golmud to perform the teleseismic P wave tomography. With their result the dynamic process in which the thick lithospheric mantle of the India plate underthrusting below the Tibetan Plateau is discussed.

Combining the data recorded by the portable broadband seismic array and the travel time data of the regional seismic network, GUO et al $(2004,2006)$ investigated the $\mathrm{P}$ wave velocity structure of the crust and upper mantle to the depth of $400 \mathrm{~km}$ below northeastern part of the Tibet, Ordos and Tianshan mountiains. Their results show that the structure of the crust and upper mantle below the northeastern part of the Tibet and Ordos has obviously laterally inhomogeneity, which occur not only between different blocks, but also within each block; the crust below the Tianshan mountains has an obvious block structure and strong lateral crustal distortion which manifest that the Tianshan crust is compressed strongly by the Tarim block. Moreover, the dynamic evolution of these two areas is also discussed in their paper.

LI et al (2006) reconstructed the 3-D P wave velocity images of the crust and upper mantle beneath Bohai Sea and its adjacent regions through a tomagraphic inversion by using $\mathrm{P}$ wave arrival times from local and distant earthquakes, with a grid spacing of $0.5^{\circ}$ (in latitude) $\times 0.6^{\circ}$ (in longitude). The velocity images reveal an evident lateral heterogeneity of the curst and upper mantle of the Bohai Sea regions. Velocity anomalies in the upper-mid crust reflect the character of surface geology.

Hearn et al (2004) imagined tomographically the seismic P wave velocity variations in the uppermost mantle beneath China using Pn wave travel time data. Different inversions performed for shorter ray path and longer ray path data sets separated the shallow and deep structure within the mantle lid. Based on their results, the relationship between the seismic velocity variations and the tectonics were discussed.

\subsection{Mantle structure studied by rece iver function and other methods}

In the recent years, the receiver function method in studying the deep structure of the Earth has been developed further.

XUE et al (2005) studied the deep structure below the western Tibetan Plateau by a method of receiver function, using seismic data recorded by 49 broadband stations along Yecheng-Shiquanhe 
cross section deployed by the Chinese Academy of Geological Science and a French scientific research center from June to November of 2006. Their result shows that there is a low velocity abnormality of S wave located at the depth of $200 \mathrm{~km}$ beneath Tianshuihai Terrain where the lithosphere of Tarim Basin and Tibet Plateau converges. WU et al (2005) obtained the upper mantle structures of Himalayas-Tibet from the migration of receiver functions of the teleseismic events recorded by INDEPTH-III. The result of migration imaging shows a dipping interface subducting northward from the depth of $100 \mathrm{~km}$ to the $410 \mathrm{~km}$ discontinuity underneath southern Tibet. ZHAO et al (2004b) analyzed the relationships between ultrahigh pressure metamorphosed belt and 3-D S wave velocity structure of the upper mantle of the eastern continent of China, and pointed out that the geometries of the velocity structure images beneath the region crossing the Dabie orogeny belt may imply that the zones thrusting downward and upward might be related to the "traces" for the subduction and exhumation process of the formation and evolution of the ultrahigh-pressure metamorphosed belt beneath the Dabie mountain. ZHENG et al (2006) collected and analyzed the data of three-component digital surface wave from 50 portable seismograph stations located in west Yunnan, China. By a method of frequency domain singular value decomposition, the polarizations of intermediate period Love waves traveling through the Qinghai-Xizang Plateau were calculated and evaluated. The result shows that there are obvious polarization anomalies, which could be due to the lateral heterogeneity of the lower crust and uppermost mantle velocity structure in the wave propagation path. Besides, theoretical arrival azimuths were computed by using the velocity model from a previous tomography study. There is general consistency between the theoretical result and the majority of the observations, although the theoretical anomalies are often smaller than the observations.

ZHAO et al (2006) used high-accuracy data of arrival times to investigate the range of variations in the travel time residuals which indicate the degree of mantle heterogeneity. It can be seen from their results that variation of the residuals amounts to $9 \mathrm{~s}$ for P phase, $11 \mathrm{~s}$ for PP phase, and $15 \mathrm{~s}$ for Pdiff phase. A large range of travel time residuals $(-6 \mathrm{~s}$ to $+9 \mathrm{~s})$ for epicentral distances shorter than 40 degrees and a smaller range of residuals $(-3 s$ to $+5 s)$ for longer epicentral distances can also be seen, indicating that the inference caused by the upper mantle and transition zone is much stronger heterogeneities than the bulk of the lower mantle.

Ai et al (2005) used three receiver function stacking methods to study the detailed crust and upper mantle structure beneath south-central Alaska. H-kappa stacking method results show that the crustal thickness under Alaska ranges from $26.0 \mathrm{~km}$ to $42.6 \mathrm{~km}$, and the $v_{\mathrm{P}} / v_{\mathrm{S}}$ ratio varies from 1.66 to 1.94 . Common converted point (CCP) stacking results along three lines show clear Moho and slab images under this subduction zone. The depths of the slab from CCP stacking images are consistent with those estimated from the Wadati-Benioff Zone (WBZ). Common depth point (CDP) stacking results shows not only the 410-, 520- and 660-km discontinuities, but also significant variations $(-30 \mathrm{~km}$ to $15 \mathrm{~km})$ in the transition zone thickness under the southwest and southeast parts of the studied region.

It can be found that the number of the researchers, who study the seismic velocity structure of the deeper part of the earth with the methods of seismic tomography and receiver function, is increasing. The existing methods were gradually improved, and the quality of the results is higher than before. The velocity structure of the Earth is the basis for studying on the Earth interior, so more works should be done on this aspect. However, the works for systematic analysis and comparison of these studies are not good enough. In the same region the results provided by different 
groups are different, but there is no further analysis and discussion. If some discussions were done, we consider the studies of this aspect would be improved.

\section{Seismic anisotropy in the mantle}

Seismic anisotropy is still a research area drawing great attention from Chinese geophysicists, new progress has also been made in the past four years.

With the three-component broadband digital seismic data obtained from the China Digital Broadband Seismograph Network (CB Network) and the United States IRIS data center, LUO et al (2004) determined SKS wave splitting parameters below more than 80 seismic stations in China and its neighboring regions using SC method (Silver and Chan, 1991). The results show that the delay times range from $0.4 \mathrm{~s}$ to $2.4 \mathrm{~s}$ with an average about $1.2 \mathrm{~s}$ in the studied region; fast wave polarization directions beneath most stations share a common preferred orientation in a same tectonic block; and the fast axes show good correlation with the past or present-day tectonic movement.

Using SKS shear waves recorded at 47 stations in Yunnan, CHANG et al (2006) calculated and analyzed the seismic anisotropy. It is shown that the fast wave polarization directions are nearly N-S in northern Yunnan and gradually change to W-E in southern Yunnan; Delay times vary from $0.58 \mathrm{~s}$ to $1.88 \mathrm{~s}$; the anisotropy layers are mainly in the upper mantle in the depth range between $67 \mathrm{~km}$ and $216 \mathrm{~km}$.

Based on the teleseismic events recorded by the Shanghai seismic array (SSA) using seismic array process technology, WANG et al (2005) calculated the splitting parameters of PpSms, P660S and SKS. The fast wave polarization directions in the crust below SSA is $67.7^{\circ}$ and the delay time is $0.26 \mathrm{~s} ; 66.6^{\circ}$ and $0.25 \mathrm{~s}$ in the upper mantle; $65.5^{\circ}$ and $0.58 \mathrm{~s}$ in the lower mantle.

RUAN et al (2004) used the pseudo-spectrum method to simulate the crust effect on the analysis of the upper mantle anisotropy. It is found that when the angle between the anisotropy orientations of the crust and the upper mantle is neither parallel nor perpendicular, the inversed results may be in large error or misjudged. Corresponding suggestions are also made in their paper.

Studies on the seismic anisotropy of the mantle are another important research direction, which provides the further information on the seismic velocity structure and the movement of the Earth's mantle. However, the works done on this aspect are decentralized. If analysis and comparison were done for the results from the same region, we consider the studies of this aspect would also be improved.

\section{Mantle discontinuities}

Mantle discontinuity is another main research direction in the past four years, and the research field is gradually enlarged.

Duan et al (2005) studied the mantle discontinuities below Changbaishan volcanic areas (CBSVA) and the Jingpohu volcanic region (JPHVR) by the method of receiver function, using the teleseismic waveform data recorded by 19 PASSCAL broadband mobile seismic stations operating nearly one year in CBSVA and other 14 stations with portable broadband digital seismographs deployed about three months in JPHVR. Results show that the 410-km, 520-km and $660-\mathrm{km}$ discontinuities exist beneath the studied area; Both the $410-\mathrm{km}$ and $660-\mathrm{km}$ discontinui- 
ties are continuous and show positive correlation; The $410-\mathrm{km}$ discontinuity is a local uplift beneath the CBSVA, and 660-km discontinuity is of the complex multi-interface; The $660-\mathrm{km}$ discontinuity descends beneath the Huichun deep earthquake area and above the $660-\mathrm{km}$ discontinuity there are some phases, which are not continuous on the two sides of the Huichun deep earthquake area.

Ai and Zheng (2003) applied a common conversion point stacking technique of receiver functions in the North China Interior Structure Project (NCISP) to image the upper mantle discontinuity structure beneath eastern China. The appearance of the $410-\mathrm{km}$ discontinuity is sharp and consistent with little influence by Western Pacific subduction slabs. The $520-\mathrm{km}$ discontinuity is relatively weak and consists of splitting phases at depths ranging from $500 \mathrm{~km}$ to $550 \mathrm{~km}$. Moreover, a double $660-\mathrm{km}$ discontinuities and a narrow depression zone are detected near a depth of $660-\mathrm{km}$.

Ai et al (2003) presented a detailed seismic study of the $660-\mathrm{km}$ discontinuity beneath northeast China using the receiver function technique. The $660-\mathrm{km}$ discontinuity is locally depressed in the region from longitude $128.0^{\circ} \mathrm{E}$ to $130.5^{\circ} \mathrm{E}$ and latitude $40.0^{\circ} \mathrm{N}$ to $44.0^{\circ} \mathrm{N}$, it then splits into multiple discontinuities in the surrounding regions.

Zang et al (2006) studied the discontinuities beneath Tonga subduction zone using deep earthquakes recorded by the Pacific Northwest Seismic Network (PNSN). The multiple discontinuities around $660 \mathrm{~km}$ beneath Tonga subduction zone are found using converted phase SdP. The amplitude ratios of the converted phase with the direct $\mathrm{P}$ wave $\left(A_{\mathrm{c}} / A_{\mathrm{p}}\right)$ are also determined. The largest number of robust converted phases with large $A_{\mathrm{c}} / A_{\mathrm{p}}$ comes from the depth range of $660 \sim 690 \mathrm{~km}$, its peak is at $680 \mathrm{~km}$; the second one appears in the depth range of $700 \sim 745 \mathrm{~km}$, its peak is at $740 \mathrm{~km}$. The two discontinuities are obviously depressed by the subduction slab. According to experimental and numerical studies, a possible explanation of the observation is that the first discontinuity is formed by the transition of $\gamma$-spinel to perovskite and magnesiowüstite and the second is formed by the transition of ilmenite to perovskite.

HE and ZHOU (2005) analyzed the global topography, the depth of the Moho (the crustal model CRUST2.0) and the depths of upper mantle discontinuities using the spherical harmonics. Based on these data, the spatial large scale distribution information has been obtained by stacking the first 4 degree modes, and the main energy distributions have been understood by synthesizing the four items with the maximal squares of amplitudes. The results show that there exists a large scale asymmetry on the scale of semi-sphere in the topographies of the Moho and the " 410 " discontinuities, and the asymmetry character of the north and south semi-spheres is more obvious than that of the west and east semi-spheres; However, there exists a scale asymmetry on the small size in the topographies of " 520 " and " 660 " discontinuities, instead of such a large semi-sphere scale asymmetry.

ZHENG et al (2007) studied the small-scale variation of $P$ waves beneath the Central Pacific using differences of the travel times between the AB and DF branches of PKP waves. They found that the observed PKP residuals consist with the predictions for Grand's (Grand et al, 1997) tomographic $\mathrm{S}$ model, and have a good correlation in the variation of their magnitude; the inferred $\mathrm{P}$ velocity variation (which is about $2 \%$ in the bottommost $200 \mathrm{~km} \mathrm{D}$ layer) is about $36 \%$ of the $\mathrm{S}$ velocity variation for the Grand model.

Mantle discontinuity is a very important research area. To obtain better results, seismic velocity study should be combined better with the study of physics of the earth's interior and the 
physics of mineral.

\section{Mantle convection}

The study of the mantle convection will be reviewed briefly in this report, because it related closely to the structure and the material properties of the mantle. More information can be found in the report of study of the Earth's dynamic.

WANG and YE (2005) applied a kinetic simulation method to perform modeling for the global lithospheric stress field induced by mantle flow. The results show that both the internal density anomalies and surface plate movements drive the mantle circulation, and a stress field will be caused at the base of the lithosphere; as a surface force, this stress field will cause lithospheric deformation itself and produces stress distribution within the lithosphere. It can be found that mantle flow plays an important role in generating and distribution of the large-scale stress field within the lithosphere.

ZHU et al (2006) developed the mantle convection model with a 3-D variable viscosity constrained by seismic wave velocity and provided a method for solving this kind of problem.

FU et al (2005a) employed a new model with different viscous ratio between the lower and upper mantle to calculate the mantle convection patterns driven by density anomaly, and discussed the relationship between convection patterns and global tectonics.

XIONG et al (2005) pointed out that the uplift and formation of the Tibetan Plateau is the dynamic consequence of the collision between the Indian and Eurasian plates. However, the collision model alone and the SW-NE compression between two plates can not explain all the tectonic features of the plateau.

FU et al (2005b) established a 3-D mathematic-physical mantle convection model driven by density anomalies, and developed the method to invert the small-scale convention in the mantle using the data of seismic tomography. Numerical results show that this method can be directly used to investigate the upper mantle small-scale convection patterns and its related problems of lithospheric dynamics. XU et al (2006) calculated upper mantle convection beneath north-west China and adjacent region using the small-scale mathematic-physical convection model driven by density anomalies in the upper mantle. It is pointed out that one of the reasons for the recent uplift of the Tianshan mountain is that the upper mantle material in this region is driven southward to the north part of Tibetan Plateau and northward to Tianshan mountain because of the divergent flow under the Tarim Basin.

LIU et al (2006) proposed a hybrid method to model the heat-creep flow concerning heterogeneous medium deformation, which combine the so-called marker-in-cell and the finite element method algorithm. The stability of numerical solutions is also investigated. With their new method, LIU et al (2007a) and Liu et al (2007b) simulated the small-scale convection of the upper mantle underneath the Tianshan mountains in China. The results show that in the upper mantle underneath the Junggar basin and North Tianshan mountains exists a counterclockwise convection, while a clockwise one exists underneath the Tarim basin and South Tianshan mountain; The scale of the convection is about $500 \mathrm{~km}$; For a normal viscosity model, the convective velocity at the top of the upper mantle underneath the Tianshan mountains in China is less than $20 \mathrm{~mm} / \mathrm{a}$; the northward extrusion of the Tarim block plays a key role in the Cenozoic Tianshan mountain building and the present-day tectonic deformation of the Tianshan range is closely related to the upper mantle convection. 
Huang and Zhong (2005) investigated the effects of sublithospheric small-scale convection (SSC) and of internal heating on seafloor heat flux and topography and mantle thermal structure, and they examined the dynamic feasibility of the plate model by formulating high-resolution two-dimensional numerical models of mantle convection with strongly temperature- and depth-dependent rheology. It is suggested from their results that the trapped heat and the SSC are responsible for the residual heat flux and topography at old ocean basins relative to the half-space cooling model predictions; for the plate model to be dynamically viable, both the SSC and significant internal heating ( $>60 \%)$ are necessary.

At present the studies on the mantle advection were limited to numerical simulation. In the future theoretical studies should be enhanced in the study of this aspect.

\section{Physical properties of the mantle material}

In the past four years, high-temperature and high-pressure experiment studies on the physical properties of mantle material have been developing steadily.

HUANG et al (2005) studied the relationship between the electrical conductivity of synthesized wadsleyite and ringwoodite and the containing water using the Kawai-1000 multi-anvil apparatus. By comparing their results with geophysically inferred conductivity, they inferred that the water contained in the mantle transition zone below Northeast China to be $0.1 \mathrm{wt} \% \sim 0.3 \mathrm{wt} \%$, which significantly exceeds the average water content in the upper mantle, suggesting that partial melting likely occurs at $410 \mathrm{~km}$ in this region. ZHANG et al (2004) conducted a shock recovery experiments on $\left(\mathrm{Mg}_{0.92}, \mathrm{Fe}_{0.98}\right) \mathrm{SiO}_{3}$ enstatite at pressure range from $60 \mathrm{GPa}$ to $110 \mathrm{GPa}$ (corresponding to temperatures of about $2300 \mathrm{~K} \sim 4800 \mathrm{~K}$ ). Their $X$-ray diffraction (XRD) and infrared absorption spectra (IR) of the recovered samples indicate that the main phase of recovered samples is single-chain structure enstatite, not the perovskite structure; There is no evidence for the existence of oxides $\mathrm{SiO}_{2}$ and $\left(\mathrm{Mg}_{0.92}, \mathrm{Fe}_{0.08}\right) \mathrm{O}$ in the recovered samples; Especially, there is no possibility for the chemical decomposition reaction of $\left(\mathrm{Mg}_{0.92}, \mathrm{Fe}_{0.08}\right) \mathrm{SiO}_{3}$ to oxides $\mathrm{SiO}_{2}$ and $\left(\mathrm{Mg}_{0.92}, \mathrm{Fe}_{0.08}\right)$ occurring under shock compression, so the high-pressure phase of enstatite-perovskite structure remains stable at the experimental conditions. LIU et al (2005) measured the elastic $\mathrm{P}$ wave velocity and quality factor value of dunite using ultrasonic pulse transmission and spectral amplitude ratio methods in a multi-anvil apparatus up to $4.0 \mathrm{GPa}$ at room temperature, and analyzed the effect of the interior structure variation of the dunite on the velocity and attenuation.

Using the observed data to study the physical properties of the mantle material is always an important study area in the geophysics, in which much progress has also been made. TANG et al (2005) carried out the magnetotelluric (MT) measurements at 62 sites in the junction area between the northeastern margin of the Qinghai-Tibet Plateau and the Ordos block along the profile of Maqing-Lanzhou-Jingbian, and analyzed the apparent resistivity, impedence phase curves, skewness and regional strike. In their paper, RRI 2-D inversion has been used for data interpretation and the electrical structure is discussed.

The rheology of the mantle is also a subject for the physical property study of the mantle. Taking into account the variation of the physical property for focal media after earthquakes, ZHU and CAI (2006) inverted the viscosities of the crust and the upper mantle in Taiwan with GPS measurements after the Chi-Chi earthquake. The preliminary result suggests that the viscosities of lower crust and upper mantle in Taiwan are $1.2 \times 10^{18}$ Pas and $3.6 \times 10^{19}$ Pas, respectively. LIN et al 
(2003) collected several tens of mantle xenoliths in the Leizhou Peninsula, and estimated their equilibrium temperature and pressure using geothermo-barometers. Then they constructed an upper mantle geotherm for the study area on the basis of the estimation results, which is lower than that of southeast Australia and much higher than the oceanic geotherm. Moreover, the rheological parameters of the upper mantle are estimated. Results show that the equivalent viscosity is within the range of $10^{21} \sim 10^{23}$ Pas, showing an obvious tendency to decrease with increasing depth.

Study on the physical properties of the mantle material under high temperature-pressure conditions in China is in quite an early stage, but progress made to date is not as good as expected. The main reason is that the equipment is backward and there is no enough funds supporting it. In recent years, some international co-operation has been conducted and good progress has been made. However, there is a big gap between the international advanced studies and those in China. To obtain better results, the study on the physical properties of the mantle material should be combined closely with the studies in related fields and international co-operation should be enlarged both in research area and personal exchange.

\section{References}

Ai Y H, Zhao D P, Gao X, et al. 2005. The crust and upper mantle discontinuity structure beneath Alaska inferred from receiver functions [J]. Physics of the Earth and Planetary Interiors, 150(4): 339-350.

Ai Y S, Zheng T Y, Xu W W, et al. 2003. A complex 660 km discontinuity beneath northeast China [J], Earth Planet Sci Lett, 212(1-2): 63-71.

Ai Y S and Zheng T Y. 2003. The upper mantle discontinuity structure beneath eastern China [J]. Geophys Res Lett, 30(21): No.2089.

CHANG Li-jun, WANG Chun-yong, DING Zhi-feng. 2006. A study on SKS splitting beneath the Yunnan region [J]. Chinese J Geophys, 49(1): 197-204 (in Chinese).

DUAN Yong-hong, ZHANG Xian-kang, LIU Zhi, et al 2005. Study on upper mantle discontinuities using the receiver function in the Changbaishan-Jingpohu volcanic area [J]. Chinese J Geophys, 48(4): 834-842 (in Chinese).

FU Rong-shan, WANG Jing-zhui, CHANG Xiao-hua, et al. 2005b. Upper mantle convection driving by density anomaly and a test model [J]. Acta Seismologica Sinica, 18(1): 27-33.

FU Rong-shan, WANG Yi, HUANG Jian-hua, et al. 2005a. Effect of rheology structure on flow patterns driven by density anomaly in the mantle [J]. Chinese J Geophys, 48(4): 824-833 (in Chinese).

Grand S P, Van der Hilst R D, Widiyantoro S. 1997. Global seismic tomography: A snapshot of convection in the Earth [J]. GSA Today, 7: $1-7$.

GUO Biao, LIU Qi-yuan, CHEN Jiu-hui, et al. 2004. Seismic tomography imaging of the crust and upper mantle beneath the Northeastern edge of the Qinghai-Xizang Plateau and the Ordos area [J]. Chinese J Geophys, 47(5): 790-797 (in Chinese).

GUO Biao, LIU Qi-yuan, CHEN Jiu-hui, et al. 2006. Seismic tomography of the crust and upper mantle structure underneath the Chinese Tienshan [J]. Chinese J Geophys, 49(6): 1 693-1 700 (in Chinese).

HE Ri-zheng, ZHAO Da-peng, GAO Rui, et al. 2006. Teleseismic P-wave tomography of lithospheric mantle beneath west Kunnun orogenic belts [J]. Chinese J Geophys, 49(3): 778-787 (in Chinese).

HE Xiao-bo and ZHOU Hui-lan. 2005. The low degree spherical harmonic analysis on the large scale topographies of the Moho and the Upper Mantle discontinuities [J]. Journal of the Graduate School of the Chinese Academy of Sciences, 22(3): 315-321.

Hearn T M, Wang S Y, Ni J F, et al. 2004. Uppermost mantle velocities beneath China and surrounding regions [J]. J Geophys Res, 109(B11): B11301.

Huang J L and Zhao D P. 2006. High-resolution mantle tomography of China and surrounding regions [J]. J Geophys Res, 111 : B09305.

Huang J S and Zhong S J. 2005. Sublithospheric small-scale convection and its implications for the residual topography at old ocean basins and the plate model [J]. J Geophys Res, 110(B5): B05404.

HUANG Xiao-ge, BAI Wu-ming, XU You-sheng, et al. 2005. Influence of hydrogen on electrical conductivity of wadsleyite and ringwoodite with its geodyltamlcs implication [J]. Acta Petrologica Sinica, 21(6): 1743-1 748 (in Chinese).

LI Zhi-wei, XU Yi, HAO Tian-yao, et al. 2006. Seismic tomography and velocity structure in the crust and the upper mantle around Bohai Sea area [J]. Chinese J Geophys, 49(3): 797-804 (in Chinese).

LIN Chuan-yong, HUANG Xiao-long, XU Yi-gang, et al. 2003. Thermal structure and rheology of upper mantle beneath Leizhou peninsula, Guangdong Province [J]. Journal of Tropical Oceanography, 2: 49-62 (in Chinese).

Liu J, Liu QY, Guo B, Song HZ. 2007a. Small-scale convection in the upper antle beneath the Chinese Tian Shan Mountains [J]. Phys Earth Planet Interi, 163: 179-190.

LIU Jie, LIU Qi-yuan, GUO Biao, et al.. 2007b. Small-scale upper mantle convection and orogeny of Tianshan Mountains in China [J]. Science in China (Series D), 50(8): $1142-1149$ (in Chinese).

LIU Jie, LIU Qi-yuan, SONG Hui-zhen. 2006. Numerical method of modeling thermal creeping flow in heterogeneous medium [J]. Chinese J Geophys, 49(4): 1 029-1 036 (in Chinese). 
LIU Wei, DU Jian-guo, XIE Hong-sen, et al. 2005. Elastic P wave velocity and attenuation in dunite up to 4.0GPa [J]. Chinese Journal of High Pressure Physics, 19(4): 293-298 (in Chinese).

LUO Yan, HUANG Zhong-xian, PENG Yan-ju, et al. 2004. A study on SKS wave splitting beneath the China mainland and adjacent regions [J]. Chinese J Geophys, 47(5): 812-821 (in Chinese).

RUAN Ai-guo, WANG Chun-yong, LI Qing-he, et al. 2004. Effect of the crust on the analysis of the upper mantle anisotropy [J]. Chinese J Geophys, 47(3): 441-448 (in Chinese).

Silver P G and Chan W W. 1991. Shear wave splitting and subcontinental mantle deformation [J]. J Geophys Res, 96: 16429-16454.

TANG Ji, ZHAN Yan, ZHAO Guo-ze, et al. 2005. Electrical conductivity structure of the crust and upper mantle in the northeastern margin of the Qinghai-Tibet Plateau along the profile Maqing-Lanzhou-Jingbian [J]. Chinese J Geophys, 48(5): $1205-1216$ (in Chinese).

WANG Jian and YE Zheng-ren. 2005. Effects of mantle flow on generation and distribution of global lithospheric stress field [J]. Chinese $J$ Geophys, 48(3): 584-590 (in Chinese).

WANG Xiao-ping, ZHU Yuan-qing, SONG Xiu-qing, et al. 2005. Mantle and crust anisotropy under Shanghai region inferred from waveform splitting of PpSmS, P660S and SKS [J]. Northwestern Seismological Journal, 27(1): $52-55$ (in Chinese).

WU Qing-ju, ZENG Rong-sheng, ZHAO, Wen-jing. 2005. The upper mantle structure of the Tibetan Plateau and its implication for the continent-continent collision [J]. Science in China (Series D), 34(10): 919-925 (in Chinese).

XIONG Xiong, FU Rong-shan, TENG Ji-wen, et al. 2005. A study of mantle dynamics of the Tibet plain [J]. Advances in Earth Sciences, 20(9): 970-979 (in Chinese).

XU Ping, FU Rong-shan, HUANG Jian-ping, et al. 2006. Upper mantle convection beneath northwest China and its adjacent region driven by density anomaly [J]. Acta Seismologica Sinica, 19(5): 552-562.

XU Zhi-qin, JIANG Mei, YANG Jing-sui, et al. 2004. Mantle structure of Qinghai-Tibet Plateau: Mantle shear zone and delamination of lithospheric plume slab [J]. Earth Science Frontiers, 11: 329-343 (in Chinese).

XUE Guang-qi, QIAN Hui, JIANG Mei. 2005. Tectonic characteristic of mantle on the west edge of Qinghai-Xizang Plateau: Receiver function inversion through West Kunlun Orgenic Belt [J]. Geological Review, 51(6): 708-712 (in Chinese).

Zang S X, Zhou Y Z, Ning J Y, et al. 2006. Multiple discontinuities near $660 \mathrm{~km}$ beneath Tonga area [J]. Geophs Res Lett, 33: L20312, doi:10.1029/GL027262.

ZANG Shao-xian, ZHOU Hui-lan, WEI Rong-qiang, et al. 2003. Structure and physical properties of the Earth's interior [J]. Acta Seismologica Sinica, 16(5): 522-533.

ZHANG Li, GONG Zi-zheng, LIU Hong, et al. 2004. Stability of ( $\mathrm{Mg}, \mathrm{Fe}$ ) $\mathrm{SiO}_{3}$-Perovskite at lower mantle pressure and temperature conditions [J]. Chinese Journal of High Pressure Physics, 18(2): 170-176 (in Chinese).

ZHAO Da-peng, Yamada A, Ohta Y. 2006. Precisely measured travel times of mantle body waves: Implications for mantle heterogeneity and tomography [J]. Earth Science Frontiers, 13(2): 037-049 (in Chinese).

ZHAO Wen-jing, XUE Guang-qi, WU Zhen-han, et al. 2004a. Fine velocity structure of the upper mantle beneath the Xizang Plateau from tomography and its geological interpretations [J]. Chinese J Geophys, 47(3): 449-455 (in Chinese).

ZHAO Zhi-xin, XU Ji-ren, XU Zhi-qin. 2004b. 3-D S wave velocity structure in the upper mantle and the mechanism investigation for the ultrahigh-pressure metamorphosed belt in the Dabie-Sulu region [J]. Acta Petrologica Sinica, 20(1): 157-164 (in Chinese).

ZHENG Si-hua, SUN Xin-lei, SONG Xiao-dong. 2007. Fine structure of P-wave velocity variations underneath the Central Pacific from PKP waves recorded at the China Seismic Network (CSN) [J]. Chinese J Geophys, 50(1): 184-192 (in Chinese).

ZHENG Yue-jun, HUANG Zhong-xian, LIIU Jian-hua, et al. 2006. Off-great circle propagation of Love waves in eastern Qinghai-Xizang Plateau [J]. Chinese J Geophys, 49(4): 1068-1 073 (in Chinese).

ZHU Shou-biao and CAI Yong-en. 2006. Inversion of viscous properties of crust and mantle from GPS temporal series measurements [J]. Chinese J Geophys, 49(3): 771-777 ( in Chinese ).

ZHU Tao, MA Zong-jin, FENG Rui. 2006. 3-D lateral variable viscosity mantle convection constrained by seismic wave velocity and its geodynamic implications [J]. Chinese J Geophys, 49(5): 1347-1 358 (in Chinese). 